\title{
FIREWALL? OR, WALL ON FIRE? A UNIFIED FRAMEWORK OF CONFLICT CONTAGION AND THE ROLE OF ETHNIC EXCLUSION
}

\author{
NILS W. METTERNICH, SHAHRYAR MINHAS, AND MICHAEL D. WARD
}

\begin{abstract}
While some borders are real firewalls against conflicts others appear like tinder just waiting for the smallest spark. Only recently has research focused on the transnational perspective of conflict and current research has focused mostly on isolated aspects of this phenomenon. In this article, we provide a unified framework for conflict contagion that takes into account receiver, sender, dyad, and network effects. This is a novel perspective on conflict contagion and our empirical results suggest that distinguishing between sender and receiver effects allows for a better understanding of spill-over effects. We provide insights that especially ethnic excluded groups impact on the risk of countries sending and receiving conflicts from its neighbors.
\end{abstract}

Word count: 10,035

\section{INTRODUCTION}

The contagion of civil conflict has received considerable attention in recent years (Murdoch and Sandler, 2004; Salehyan and Gleditsch, 2007; Gleditsch, 2007; Cederman, Girardin and Gleditsch, 2009, Kathman, 2010, Beardsley, 2011; Black, 2013; Danneman and Ritter, 2014; Garcia and Wimpy, 2015). In the context of the Arab Spring, the issue of conflict spillovers has received renewed public attention, but it has been subject to a larger scholarly debate since the 1970s (Starr and Most, 1976; Hill and Rothchild, 1986). The wave of decolonization wars at the end of the 1960s and in the beginning of the 1970s, the revolutions in Eastern Europe at the end of the 1980s and beginning of the 1990s, or the conflicts in the Great Lakes region in Central Africa (Young, 2006) have all been cited as examples of conflict contagion. Current research highlights that conflict contagion is a complex process that is conditional on both domestic and international factors (Maves and Braithwaite, 2013). In fact, existing research suggests that civil contagion is a fundamental

The authors want to thank participants of the Peace Science Meeting in Savannah, GA, October 26-27 2012, the Annual Convention of the International Studies Association in San Francisco, CA, April 3-6 2013, and ENCoRe meeting in Amsterdam, April 23-26 2013 for their helpful comments. We also thank Will Moore, Erika Chenoweth, Simon Hug, Kristian Skrede Gleditsch, and the anonymous reviewers for their constructive comments. This project was undertaken in the framework of an initiative funded by the Information Processing Technology Office of the Defense Advanced Research Projects Agency aimed at producing models to provide an Integrated Crisis Early Warning Systems (ICEWS) for decision makers in the US defense community. The holding grant is to the Lockheed Martin Corporation, Contract FA8650-07-C-7749. Nils W. Metternich acknowledges support from the Economic and Social Research Council (ES/L011506/1). Working paper version: Please do not cite. 
Firewall? Or, Wall on Fire?

aspect of understanding the phenomena of civil conflict more generally. Despite this focus on conflict contagion, limited attention has been paid to the conceptualization of conflict contagion. In this article, we provide a unified theoretical conceptualization of civil conflict contagion and an empirical estimation strategy. This framework allows us to draw attention to the extent to which excluded ethnic groups in a country increase the risk of sending and receiving conflict.

Civil conflict contagion poses a social scientific challenge. This challenge is highlighted when comparing research on civil conflict contagion to studies on disease contagion. Unlike diseases, civil conflicts involve strategic actors that operate in a social environment. Hence, conflict contagion is a truly social phenomenon that involves actors making strategic decisions on whether contagion takes place or not. For example, governments can support rebel operations in neighboring states or not, while bacteria do not make conscious decision about their hosts. Also, in the case of diseases the mechanism of contagion is often identified in great detail and given that knowledge, we can study and predict the actual spread of the disease. We lack a similar level of knowledge in the context of civil conflicts, where multiple contagion mechanisms are suggested (and many are likely to operate simultaneously) and hence it becomes more challenging to predict where and when conflict is likely to spread (Forsberg, 2014a). Thus, if we accept that multiple contagion mechanisms exist, it becomes necessary to consider a model of conflict contagion that can incorporate multiple contagion effects and weigh them according to their importance.

We theoretically identify the elements that are part of demonstration effects leading to conflict contagion. We analyze how the political exclusion of ethnic groups impacts demonstration dynamics and subsequently the spread of conflict. We use a statistical approach ( effect actor-specific, dyad-specific, and third-order effects have on conflict contagion. While current scholars mostly construct a weight matrix that matches their theoretical contagion effect without considering other possible contagion mechanisms, we account for multiple aspects of contagion and provide improved predictions of conflict contagion. This also allows us to highlight the impact ethnic exclusion has on the risk of sending and receiving conflict. Finally, current analysis of conflict contagion cannot differentiate between contagion that stems from a small number of dyads or broader regional effects, or even identify particular actors or dyads that drive contagion. In contrast, we are able present a multi-faceted picture of conflict contagion.

Unlike existing contributions on civil conflict contagion, we focus on contagion as our dependent variable and not civil war onset. Thus, rather than analyzing how conflicts in neighboring or similar 
Firewall? Or, Wall on Fire?

countries affect civil conflict onset per se, we want to explain the conditions under which contagion takes place. This perspective allows us to capture the sender, receiver, dyad, and network effects of civil conflict contagion.

\section{Contagion Dynamics in Civil CONFliCts}

In the context of civil war contagion, it is important to highlight that spatial clustering in conflict does not necessarily imply contagion (Buhaug and Gleditsch, 2008). Contagion pertains to a causal process in which behavior or characteristics of individual units impacts on the behavior and characteristics of other units. Hence, contagion implies that the observed units are not independent from each other. Clustering can be seen as a more general, descriptive phenomena that can be caused by contagion, but may also be related to the simple fact that a set of countries have similar individual attributes that are related to certain neighborhoods or regions. For example, factors believed to impact the risk of civil conflict frequently cluster geographically (Gleditsch, 2002a) and therefore might lead to conflict clustering without any conflict contagion (Buhaug and Gleditsch, 2008).

In a very broad sense, we can distinguish between internal (receiver) and external (sender) determinants of contagion. Internal factors relate to behavior or attributes of a country or actors within a country that decrease or increase the risk of contagion. For example, Hill and Rothchild (1986) present a theory of conflict contagion in which conflict in one country can heighten the sense of a shared identity within another county and develop a clearer sense of this identity. However, they highlight that this contagion mechanism of social learning can only work if a latent and disaffected identity group exists and the domestic government cannot control the information about conflicts in other countries. High state capacity is also argued to prevent conflict contagion, as strong states can protect their borders and have the ability to react to the demands of their population (Braithwaite, 2010). This example demonstrates that receiver/internal attributes play an important role in the contagion of conflict. Interestingly sender effects are less well studied. In most theoretical and empirical research the sender appears only as an external shock (civil conflict in the sender) or as part of a dyad (similar attributes with the receiver). To our knowledge no study exists that explicitly focuses on sender attributes (infectiousness) that contribute to the risk of contagion. For example, we do not know whether poor countries are more likely to spread conflict than rich 
Firewall? Or, Wall on Fire?

countries. Finally, we want to stress that sender and receiver effects are likely to interact with each other as Maves and Braithwaite (2013) highlight.

In regard to economic policies Simmons and Elkins (2004) discuss four mechanisms of policy diffusion that are also useful to categorize conflict contagion mechanisms. Coercion is the first mechanism and refers to contagion that is often intentionally initialized by the sender. Coercive contagion frequently takes place through external sponsorship of insurgencies Gleditsch, Salehyan and Schultz, 2008, Cederman, Girardin and Gleditsch, 2009; Schultz, 2010). What makes this behavior lead to contagion is a tit-for-tat dynamic that can trigger civil conflict in the initial sender state (Beardsley, 2011).

The second mechanism highlights that civil war actors can learn across borders (Horowitz, 1985). The learning mechanism in the context of civil conflict contagion varies from social learning mechanisms to more strategic learning variants. What is interesting about the learning mechanism is that it allows for conflict contagion beyond the geographic dimension. Hill and Rothchild (1986) stress in their theory of social learning that the transmitted information can be received through radio or television. In the context of today's media this would include internet-based services, which are proclaimed to have played a role in the Arab Spring. What differentiates the different learning approaches is whether they stress the information update aspect of learning in the sense of Bayesian updating, or whether learning is rather connected to changing the salience of identities and thus the fundamental ability to act collectively (Hill and Rothchild, 1986).

Competition refers to pressures that behavior in an individual country places on others. In context of civil war one could argue that peace leads to economic advantages and therefore states compete for being more peaceful than others or at least as stable as economic competitors. This could explain the prominence of peaceful as well as conflict regions, where equilibrium behavior might be very different. Emulation is the fourth mechanism and refers to behavior that is inspired by example, but which does not involve learning mechanism such as information updating or social learning. In the context of trans-border ethnic kinship, Forsberg (2008) argues that kin group inspiration can trigger conflicts in neighboring states. While she highlights an informational aspect to this, the actions of the ethnic kin seem primarily motivated by emulation.

Franzese and Hays (2008) add a fifth category to the diffusion mechanisms proposed by Simmons and Elkins (2004): migration. The idea that refugee flows can lead to conflict contagion has been the subject of a number of projects that elude to different diffusion mechanisms. Salehyan and Gleditsch 
Firewall? Or, Wall on Fire?

(2007) suggest several causal mechanisms. Refugee flows may imply the direct "importation" of combatants, arms, and ideologies from neighboring states that facilitate the spread of conflict. Rather than fighting openly with the host government, refugee populations can provide resources and support to domestic opposition groups of a similar ethnicity or political faction. Refugee flows can change the ethnic balance in a country, sparking discontent among local populations toward the refugees as well as the government that allows access. Further, refugees may pose actual or perceived negative economic externalities by competing with locals over scarce resources such as employment, housing, land, or water.

\section{ETHNIC EXCLUSION AND CIVIL CONFLICT CONTAGION}

A particular focus in the conflict contagion literature has been on the role of ethnicity (Moore and Davis, 1997; Fox, 2004). There is increasing evidence that ethnic linkages across borders increase civil conflict onset (Cederman et al., 2013). Existing studies mostly focus on receiver and dyad effects, but pay little attention to sender effects or network effects. Moreover, there are no studies to our knowledge that try to separate sender, receiver, dyad, and network effects in the context of ethnicity and civil conflict.

While our understanding of the role of trans-national ethnicity and civil war onset has dramatically increased (Cederman et al., 2013), we know much less about the effect of ethnic exclusion on civil war contagion. Kuran (1998) argues that ethnicity impacts on conflict contagion through demonstration effects. In this line of reasoning ethnic groups challenge their government, if they observe ethnic groups in other countries, but in similar political situations, opposing their respective government. That means not only ethnic linkages per se matter (De Groot, 2011), but the political characteristics of these linkages. Observing the violent actions of similar groups leads to an awareness of their grievances and triggers violent conflict. In an extension of this argument Beiser (2011) stresses the role of similarity in political exclusion and the extent to which the actions of other groups can be observed (e.g. media access). In addition, Gurr (1993) argues that ethnic ties are not only important to whether conflicts spread, but also the tactics employed. These are clearly dyad oriented explanations that focus on the similarity of units to explain conflict contagion.

The argument of receiver characteristics can also be found in the current literature. For example, Forsberg (2008) argues that ethnic polarisation (few groups of similar size) increases the prospects of gaining power and makes groups more susceptible to demonstration effects in neighbouring 
Firewall? Or, Wall on Fire?

countries. However, Forsberg (2008) believes that this receiver effect is conditioned by ethnic kinship ties across borders (compare Buhaug and Gleditsch, 2008), but does not find empirical support for this argument. In an extension of her work, Forsberg (2014b) argues that demonstration effects are most likely when initial conflicts have been successfully ended for the challenger. This is probably one of the few arguments that actually stresses sender characteristics even though she finds little empirical support for this idea. In addition, she highlights that the characteristics of the ethnic kin in the conflict receiving state should matter and provides empirical evidence that the status and size (see also Cederman, Girardin and Gleditsch, 2009) of the ethnic kin in the receiving state has an impact on contagion.

\section{A network PERspective on Civil CONFliCt CONTAGion AND ETHNiC EXClusion}

We draw on the existing literature that stresses the role of demonstration effects in the context of conflict contagion. In contrast to existing theoretical approaches we pursue an agency oriented approach by isolating the role of sender, receiver, dyad, and third-order effects involved in demonstration dynamics. This allows us to contribute to the existing literature by formulating hypotheses in regard to the individual elements that are involved in demonstration dynamics. We propose a theoretical framework that captures the role ethnic exclusion has on demonstration effects that impact civil war contagion. First, we highlight the role of sender effects that have received little attention in the current literature. We identify how conflictual countries that pursue ethnic exclusion contribute to the spread of conflict through demonstration effects. Second, we focus on the conditions under which these demonstration effects are more likely to reverberate in countries with ethnically excluded populations and lead to conflict. Third, we allude to the additional risk of conflict contagion between states that share ethnic exclusionary policies. Finally, we argue that third-order network effects, which might be conceptualized as conflict traps, have a further conflict enhancing role in contagion dynamics. Drawing attention to a precise conceptualization of civil conflict contagion will not only allow us to identify different ways ethnic exclusion impacts on the spread of conflict, but also demonstrates that current research has not yet explored all facets of this phenomenon. The theoretical section makes a strong argument that civil conflict contagion can best be captured by a unified network perspective on civil war contagion that distinguishes between sender, receiver, dyad, and third-oder effects. 
Firewall? Or, Wall on Fire?

An important element, when focusing on demonstration effects in the context of civil conflict, is the initial sender who demonstrates violent behavior. We argue that conflicts have certain characteristics that make them more likely to be contagious, independent of potential recipients. We will refer to these characteristics or behaviors of already ongoing conflicts as sender effects. Surprisingly, the extant civil conflict literature has little to say about sender characteristics that make it more likely that conflicts spread. But an example from the health sciences might further stress the role of conflict senders. In the medical context, it is a simple truth that there is no contagion without a patient zero and there is no contagion if patients who have contracted the disease, stay at home or are treated in isolation. This implies that the behavior and attributes of those that have contracted the disease play a major role in preventing its spread. We propose that similar dynamics apply to conflict contagion through demonstration effects.

We argue that conflicts that relate to grievance based incompatibilities are more likely to reverberate in other countries. Grievances that relate to political exclusion are more likely to be shared across countries than specific governmental issues such as coups d'état, with the restriction that some coups d'état might also be driven by political grievances. Hence, contentious issues that individuals and groups in other countries can relate to are more likely to spread. However, grievance based incompatibilities can come in many different forms, but they share the underlying notion of existing political inequalities. As such ethnic exclusionary policies are one driver of group-based grievances, but they can be seen as a subtype of group-based political grievances that can form along many different political cleavages. Therefore, ethnic exclusion induced struggles should have a general demonstration effect on a variety of countries where grievance based incompatibilities exist. Thus, we propose that conflicts within countries having politically excluded groups are more likely to spread because they involve fundamental grievances that reverberate not only with other ethnic groups in neighboring countries, but with politically excluded groups more generally.

Hypothesis 1: Conflicts in countries with excluded ethnic groups are more likely to spread.

Having specified how ethnic exclusionary policies impacts on sender effects, we now turn to the the role of receiver characteristics. While the literature has largely ignored sender effects of civil conflict contagion, receiver effects are much better understood. Indeed, many authors have highlighted the role of state capacity, border length, and other characteristic that might increase or decrease the probability of experiencing a conflict spillover (Braithwaite, 2010; Maves 
and Braithwaite, 2013). It is widely argued that actors can behave in particular ways or have certain characteristics that decrease/increase their risk of experiencing a civil conflict. For example, Danneman and Ritter (2014) suggests that governments implement conflict mitigating policies when they expect conflict spillovers.

We argue that ethnic exclusion increases the propensity of ethnic groups and its members to act upon demonstrations of violence against regime induced political grievances. To some extent this argument is similar to existing contributions in the context of conflict onset Cederman, Wimmer and Min 2010), where ethnic exclusion is identified as an important factor that increases the vulnerability of a country to experience conflict. Excluded ethnic groups are more likely to challenge the government because of political grievances or through the resulting decrease in opportunity costs. However, we argue that politically excluded groups not only react to ethnically grievance based conflict, but respond to political inequality struggles more general. Thus, we propose that ethnic groups identify with political struggles that address similar political grievances, but not necessarily the same ethnic grievances. Again, this perspective stresses the more general aspect of political grievances and that groups can relate to these fundamental struggles independent of its specific type. Importantly, this means that excluded groups not only respond to the actions of related groups (Beiser, 2011; Cederman et al. 2013), but more generally to conflicts in other countries.

Hypothesis 2: Countries with excluded ethnic groups are more likely to receive conflicts.

In the context of demonstration effects, we have now identified the sender and receiver specific aspects of ethnic exclusionary polices that contribute to conflict contagion. However, we also argue that there are dyadic conditions under which demonstration effects are more likely to effect conflict spillover. In line with existing research, we propose that common ethnic grievances make it more likely that the dynamics of demonstration effects can effectively take place. Similar ethnic grievances make it more likely that members of ethnic groups can relate to struggles in other countries and emulate the demonstration of violence against political inequality. This argument is in line with existing research that attenuates the link between ethnic kin and civil conflict contagion (Beiser, 2011; Cederman et al., 2013) by stressing that socio-political relationships drive conflict contagion. These relationships are argued to matter for demonstration effects (Kuran, 1998; Forsberg, 2008, Beiser, 2011), learning, and trans-border support (Cederman et al., 2013). 


\section{Firewall? Or, Wall on Fire?}

In the context of our study, the main implication of the dyad centered argument is that conflicts are more likely to spread between countries with excluded ethnic groups as they share a similar political status. High perceptions of similarity across borders are frequently argued as promoting learning and demonstration dynamics (Forsberg, 2014b). Various authored have argued that this identification with proximate (Kuran, 1998; Forsberg, 2014b) and also non-proximate ethnic groups (Beiser, 2011) make it exceedingly more likely that members of discriminated or excluded groups take up arms against the government. This implies that socio-political distance might be a more important dimension than merely geographic proximity Gleditsch, 2007, Buhaug and Gleditsch, 2008). Especially, Kuran (1998) argues that ethnic conflict abroad can inspire other ethnic groups to raise demands vis-à-vis their respective governments. Forsberg $(2014 b)$ further refines this argumentation and suggests that ethnic groups that share the same ethnic grievances (e.g. lack of political and cultural autonomy) are more likely to view these discriminating practices worth fighting over if one ethnic groups starts challenging the government. This implies that conflict is more likely to spread between countries that politically exclude groups based on their ethnic membership.

Hypothesis 3: Conflicts are more likely to spread between countries with excluded ethnic groups.

Finally, we focus on third-order dependencies within conflict contagion, which go beyond secondorder dependencies such as reciprocity among dyads. Theories of civil conflict contagion have not assessed the role of third-order dependencies, which include balance, transitivity, and clusterability (Wasserman and Faust, 1994). Theoretically accounting for third-order effects is important because they can capture conflict contagion dynamics that go beyond actor or dyad related factors. For example, a country might become the host of a particular rebel organization that spreads across many other countries, e.g. Taliban in Afghanistan or the Islamic State in Syria. However, we are frequently unable to observe all the factors that make a country a central node in a conflict network, but still want to model these unobservable network factors. Especially, in the context of demonstration effects there might be unobservable factors that make it more or less likely that countries will react to demonstrations of political violence. We shortly discuss different types of third-order effects and outline their implications for conflict contagion mechanisms. While existing studies have looked at dyadic and to certain extend triadic relationship (Cederman, Girardin and Gleditsch, 2009), to our knowledge, this is the first study that explicitly explores third-order relationships in the context of ethnicity and conflict. 
Firewall? Or, Wall on Fire?

We start by discussing the concept of balance, which was suggested by Heider (1946) in the context of his work on how individual attitudes and perceptions are influenced by their social environment. He was especially interested in whether people with similar attitudes towards each other are likely to display similar attitudes towards others. For example, whether friends have positive and negative attitudes towards the same people. More formally, in a setting with three actors $i, j$, and $k$, balance occurs either when the relationships between the three actors are all positive, all negative, or two negative relationships exist such that two friends dislike the same person. Translating this idea to the context of civil conflict, balance would either exist if no country spreads conflict, all countries spread to each other, or two countries infect each other but both countries do not spill conflict in a third country. There is little reason to believe that balancing is a powerful driver of conflict contagion, when comparing it to other network dynamics.

More likely are situations where conflict clusters form in different regions. This phenomena is typically called clusterability, which highlights that within a larger network, there might be subsets of actors that all join positive or all join negative relationships but do not do so with other actors. For example, in a network with six actors $a_{1}, \ldots, a_{6}$ we might observe that actors $a_{1}, a_{2}, a_{3}$ all share positive relationships, but none or few of them share positive relationships with $a_{4}, a_{5}, a_{6}$, whereas $a_{4}, a_{5}, a_{6}$ all share positive relationships. In this case, we can identify two separate clusters of actors. This kind of clustering arises in the context of civil conflict contagion, if regional contagion processes exist that are separated from each other.

Another network scenario that is often described in the the literature are conflict traps, where conflict is passed around the same set of countries. This pattern is similar to the network concept of transitivity, which follows the logic "a friend of a friend is a friend". In the context of civil conflict contagion, transitivity would imply that if conflict spills over from country $i$ to $j$ and from $j$ to $k$, it is also likely that conflict contagion takes place between $j$ to $k$. In a sense this pattern describes a regional conflict trap, where contagion is passed among a set of actors without immunity developing among them (Young, 2006).

\section{A UNIFIED MODEL OF CIVIL CONFLICT CONTAGION}

Our theoretical argument highlighted that the spread of conflict through demonstration effects needs to consider the different elements of this causal mechanism. First, we proposed that sender and receiver specific ethnic grievances foster the effective operation of demonstration dynamics. In 
Firewall? Or, Wall on Fire?

addition, we argued based on the existing literature that shared ethnic grievances make it even more likely that ethnic groups react to the demonstrations of violence in other countries. Finally, we highlighted the possibility of unobserved third-order effects that impact on the spread of conflict. In this section, we implement a statistical approach (Hoff, 2005) that allows us to empirically identify the different aspects of the theoretical argument and assess their individual impact on civil conflict contagion.

We introduce notation that is helpful to keep track and fully capture sender, receiver, dyad, and third-order dependencies highlighted in the previous section. Let us first consider a contagion matrix $C$ that indicates whether a conflict in country $i$ has spilled over to country $j$. $C$ is a $n \times n$ matrix with the contagion senders in the rows and the receivers in the columns. Contagion takes place if country $i$ is experiencing an ongoing conflict at time $t_{1}$ and country $j$ is experiencing a conflict onset in period $t_{1}$. In the case of contagion from $i$ to $j, c_{i, j}$ is coded as 1 , whereas a contagion from $j$ to $i$ would be indicated in $c_{j, i}$. Thus, $C$ is a directional matrix that enables us to identify major senders and receivers of civil conflict. Depending on data availability and the research question $C$ can either be binary indicating whether a spillover has taken place, or a count of the number of spillovers between $i$ and $j$. In this case $c_{i, j} \in(0,1)$ is composed of the occurrence of a spillover within a set time period. We are interested in whether $c_{i, j}$ is equal to one, that is, whether contagion has taken place.

5.1. Generalized Bilinear Mixed Effects Models (GBME). Our method to estimate contagion risk is a latent space approach which separates sender, receiver, dyad, and network effects by decomposing the random effect. We implement a generalized bilinear mixed effects model (GBME) developed by Hoff (2005) that captures these network dynamics and which has been further extended by Ward, Ahlquist and Rozenas (2012) to account for time dynamics. The GBME approach that we implement allows for the explicit modeling of first-order (sender/receiver) and second order (dyad) effects. In addition, the model includes sender, receiver, and dyad specific random effects, which capture un-modeled variance, for example from omitted or unobserved variables, in regard to the outcome matrix. This is important if specific senders or dyads have a much a higher or lower propensity to contribute to conflict spillovers than expected, conditional on the covariates entered in the model specification. However, the main attraction of the GBME model is its ability to capture third-order network dynamics. It does so through a bilinear random effect component, which describes the variance in the outcome matrix that can be explained by similar behavior of 
Firewall? Or, Wall on Fire?

$i, j$. For example, if country $i$ is more likely to send conflict to country $j$, because both country $i$ and $j$ are likely to receive conflicts from or send conflicts to the same set of countries, such patterns are captured by the bilinear random effect component.

One of the shortcomings in the static GBME approach is the incorporation of time-varying covariates. To address this limitation (Ward, Ahlquist and Rozenas, 2012) allow for dynamic updating of the latent factors. Their solution is to sequentially estimate the model using a temporal lag of the bilinear terms as dyad-level covariates in the current time period. The estimated latent positions, in models that include the temporal lag of the bilinear terms, are the short-run changes from the prior time period. This model leverages "poor-man's exogeneity" to identify this model and possible endogeneity is ruled out. Nonetheless, this model represents an improvement over previous advances as it allows for the inclusion of time-dependencies.

5.2. Model specification. In order to estimate the GBME model we use event data from the Integrated Crisis Early Warning Systems (ICEWS) project to determine whether in a given month a country is experiencing violent insurgency or rebellion events. The ICEWS data is based on natural language processing of a continuously updated harvest of news stories, primarily taken from Factiva, a proprietary repository of news stories from. The event coder, transforming text to relevant events, is called JABARI, a java variant of TABARI (Text Analysis By Augmented Replacement Instructions), which was developed by Philip Schrodt and colleagues 11 From this event data we identify high intensity events are taking place between the government and insurgent/rebellious organizations. See O'Brien (2010) and Ward et al. (2013) for a description of the ICEWS project; the data are available at Boschee et al. (2015).

In a second step we code a contagion event $y_{i, j}=1$ if country $i$ is experiencing a high intensity insurgency/rebellion event in month $t_{i_{0}}$ and a similar event subsequently takes place in country $j$ in month $t_{j_{1}}$, where no conflict is ongoing in $t_{j_{0}}$. To bring our notion of contagion in line with existing civil conflict research we restrict contagion to only occur between adjacent countries. We code conflict contagion using the monthly-level event data provided by the ICEWS dataset. We determine whether there was any contagion event between dyads from the periods of 2001 to 2005 and 2006 to 2010. This produces two matrices where the $c_{i, j}$ in each represents whether there

\footnotetext{
${ }^{1}$ See http: //eventdata.psu.edu/
} 
Firewall? Or, Wall on Fire?

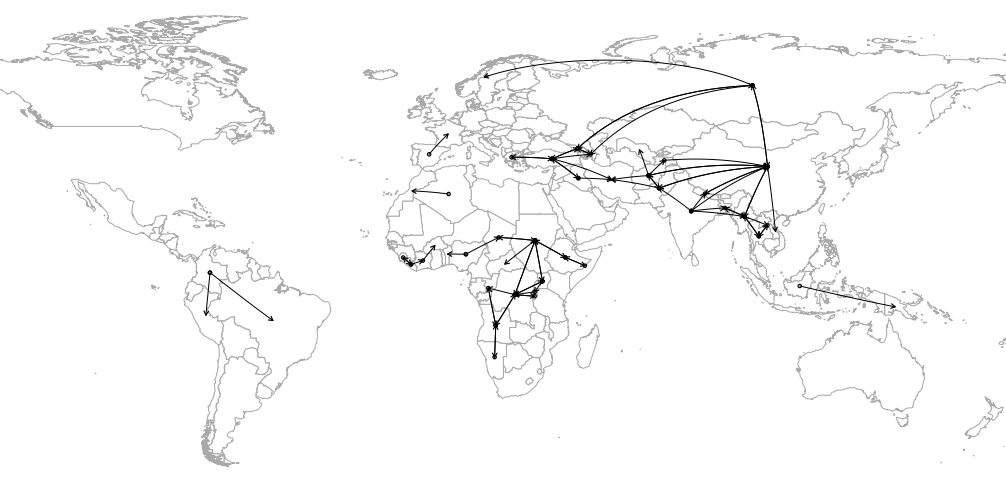

Figure 1. Conflict Contagion, 2001-2005.

was a contagion event sent from $i$ to $j$ in the time period for that matrix. ${ }^{2}$ Figure 1 maps the dependent variable for the first observation period (2001-2005) $!^{3}$ The map also provides insights to the directionality of contagion that we explain in our empirical model $4^{4}$

To further illustrate our dependent variable, let us turn to the Democratic Republic of Congo between 2001 and 2005. According to our data, there are five countries that experienced renewed high intensity insurgency/rebellion events after such events occurred in the previous month. These are the Congo, Uganda, Burundi, Angola, and Sudan. Similarly, there are five countries that experienced high intensity insurgency/rebellion in a month before such events occurred in the DRC. These were Uganda, Burundi, Angola, Sudan, and Rwanda. This example seems to support existing arguments about conflict traps especially in the Great Lakes Region (Young, 2006). Four countries, Uganda, Burundi, Angola, and Sudan, send and receive high intensity insurgency/rebellion events from the DRC, which would be in line with such a pattern. In addition, there are two countries, Congo and Rwanda, which do not show a reciprocal pattern with the DRC.

With these main explanatory variable, we want to assess the degree to which civil war contagion is conditional on the exclusion of politically relevant ethnic groups from access to central state power. We use data from the Ethnic Power Relations (EPR) dataset (Cederman, Wimmer and Min, 2010) to measure dyadic, sender, and receiver characteristics of ethnic exclusion. To construct the dyadic measure, we construct a matrix where if both $i$ and $j$ have any politically relevant ethnic groups that are excluded from power then the $i, j$ cross-section equals one and zero otherwise. For the

\footnotetext{
${ }^{2}$ Sparsity of contagion events left us unable to construct a separate matrix for each year as in some years there were simply no contagion events. The longer time periods implies that we are unlikely to capture the consequence of short-term changes in the explanatory variables and its consequences on conflict contagion.

${ }^{3}$ ICEWS includes all countries that are: a) not the US and b) independent with a population greater than a million. ${ }^{4}$ We want to highlight that our dependent variable only captures "potential" contagion events. Our empirical model analyzes to which extent we can explain the observed variance with variables that we theoretically claim to imply "true" contagion rather than clustering.
} 
sender $i$ and receiver $j$ covariates, we create a logged count variable for the number of politically relevant ethnic groups that are excluded from power. Basic summary information about these variables is included in the online appendix.

In addition to this variable, we introduce other covariates to capture sender $i$ and receiver $j$ effects. Specifically, we include a country's logged GDP per capita, logged population (both form the World Development Indicators), the proportion of mountainous terrain, GDP growth in the past 5 years (Gleditsch, 2002b), and Polity score (http://www.systemicpeace.org/polity/polity4. htm). Data for mountainous terrain is taken from the replication dataset provided by Fearon and Laitin (2003). They use the proportion of the country that is "mountainous" according to the codings of geographer A.J. Gerard $!^{5}$ For each of the covariates, we include data from the beginning of each of the time periods. For example, when predicting contagion events from 2001 to 2005, each of the covariates is measured at 2001 levels. After we incorporate these measures we are left with 167 countries for our analysis.$^{6}$

5.3. Results. The results from the GBME estimation can be found in Figure 2 and Table A2 in the online appendix. Before turning to our main results, we discuss the estimated effects of our control variables. In regard to economic development, we find that a higher GDP per capita decreases the probability of a country to send or receive conflicts. This effect can be found both from 2001 to 2005 and 2006 to 2010. Countries with larger populations are associated with an increased risk of sending and receiving conflict, even though the credible intervals include zero in the period between 2006 and 2010. Contrary to the existing literature (Maves and Braithwaite, 2013), we do not find a consistent effect of political institutions on the risk of conflict spillover. GDP growth generally increases the probability of conflict spillovers, but the again the credible intervals include zero except for sender effects between 2001 and 2005. Finally, the proportion of mountainous terrain does not have a consistent effect across both models.

Turning to our main findings, we first investigate the dyadic effects $i, j$. The estimates for excluded population in Figure 2c do not show that contagion is more likely to occur when both $i$ and $j$ contain excluded populations. The credible intervals in both time periods include zero and we do not find strong evidence in support of our hypothesis that the risk of conflict contagion is

\footnotetext{
${ }^{5}$ To estimate mountainous terrain for countries not included in the replication dataset, we use the difference between the highest and lowest point of elevation. This is the same approach that Fearon and Laitin used to deal with missingness in the codings from Gerard.

${ }^{6}$ Missing data are imputed using a copula based approach sbgcop developed by Hoff (2007).
} 
Firewall? Or, Wall on Fire?

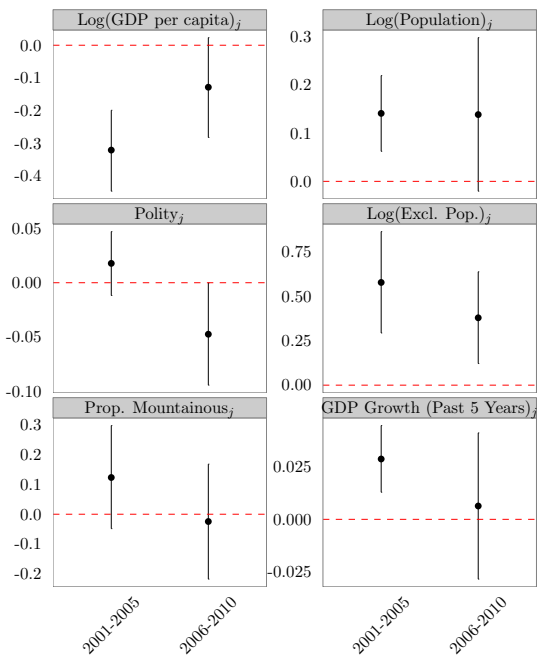

(A) Sender Effects

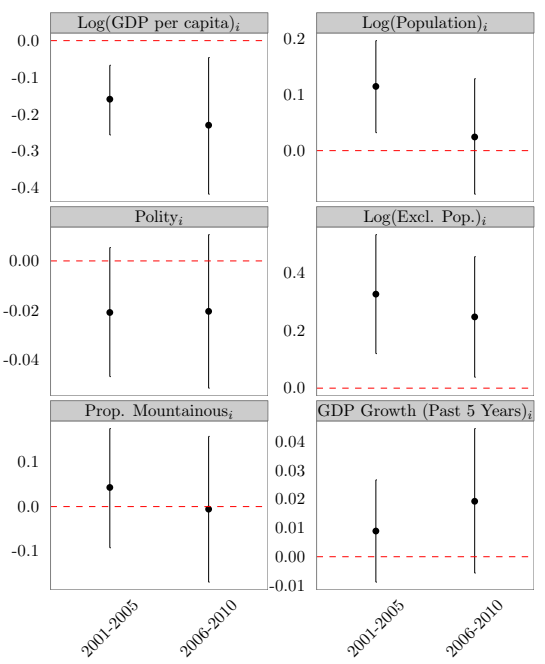

(B) Receiver Effects

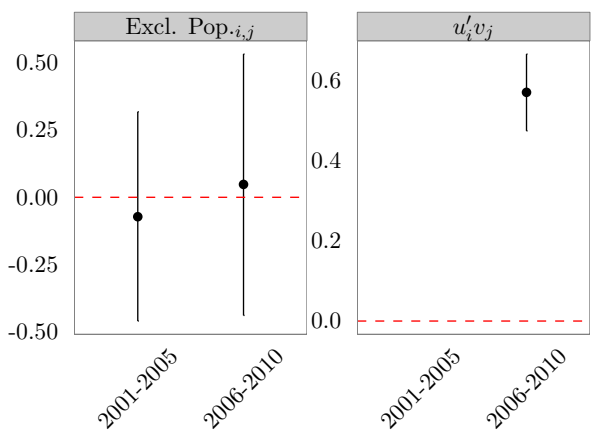

(c) Dyadic Effects

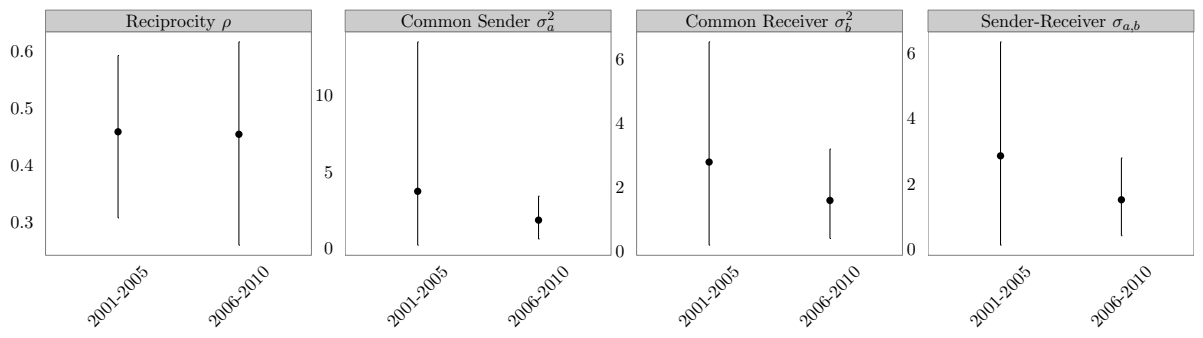

(D) Dependencies

Figure 2. Sample: $16^{7}$ countries. Dependent variable: Occurrence of contagion event between 2001 to 2005 and 2006 to 2010. Independent variables: Each IV below measured at initial value of time period. The 95\% credible interval of each parameter is represented by the vertical line and the dot represents the mean estimate. A red line is shown to denote zero. 
Firewall? Or, Wall on Fire?

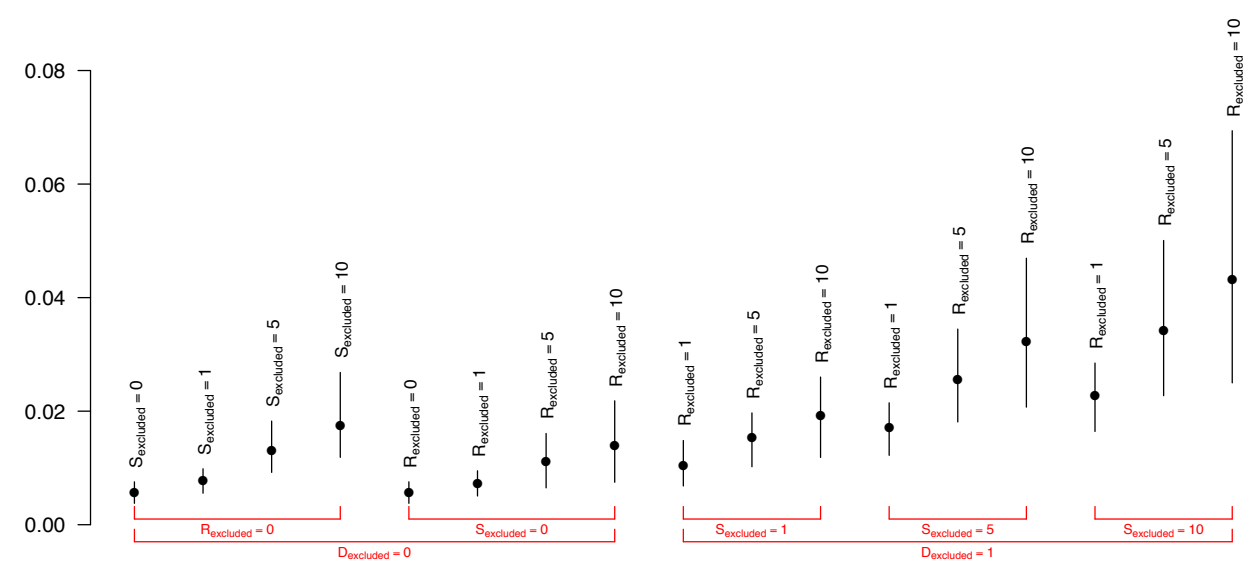

(A) $2001-2005$

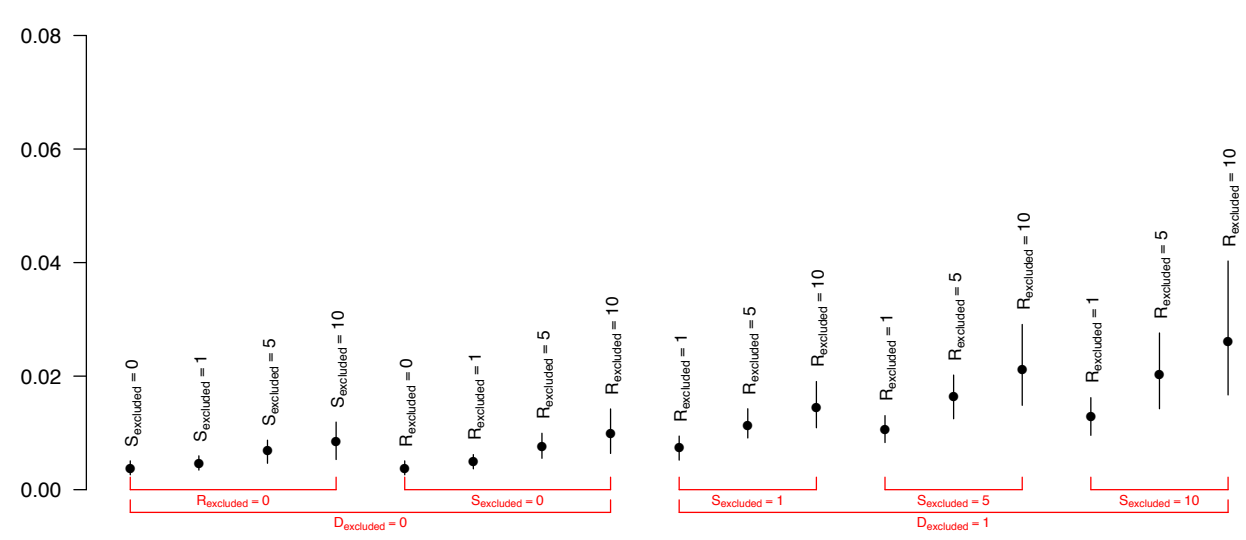

(в) 2006-2010

FiguRE 3. Predicted probabilities of conflict contagion for different sender and receiver values of politically excluded ethnic groups. If both sender and receiver politically exclude ethnic groups, the dyad indicator takes a value of one.

higher if countries $i$ and $j$ both exclude ethnic groups from political power. In contrast, the lagged products of the latent positions $\left(u_{i}^{\prime} v_{j}\right)$ has a positive and precise effect in predicting the probability of conflict contagion from 2006 to 2010 . This indicates that countries that sent and received conflict from similar countries between 2001 and 2005 are more likely to send and receive conflicts from each other between 2006 and 2010. Thus, as we will further demonstrate, third order network effects positively impact on conflict contagion risks in the future time period. This provides initial support for the idea of regional conflict traps.

Next, we assess sender $i$ effects, shown in Figure 2a, by investigating the characteristics that make a country infectious in regard to civil conflicts. To our knowledge this is the first detailed presentation of sender effects in the conflict research literature. Our results suggest that countries 


\section{Firewall? Or, Wall on Fire?}

with excluded ethnic groups are more likely to spread conflicts. More precisely, as the number of excluded ethnic groups increases, the more likely a country will spread its conflict. This positive effect holds across both observation periods and is in line with Hypothesis 1.

On the receiver side $j$ (Figure 2b), we find that excluded ethnic groups make it more likely that a country receives conflict. Again, this positive receiver effect holds for the time periods 2001 to 2005 and 2006 to 2010. The estimated receiver coefficients are comparable to the sender coefficients, highlighting that sender and receiver characteristics have a similar impact on civil conflict contagion. Hence, excluding ethnic groups from power increases both the infectiousness and vulnerability to conflict spillovers.

While the initial results support our argument that sender and receiver effects matter, we did not find support for the idea that countries that both exclude ethnic groups are more likely spread conflict among each other. But as both sender and receiver characteristics matter, two countries ij that politically exclude ethnic groups will have a higher risk of conflict contagion. To assess this effect and to gain a better sense of the substantial contagion effects of excluded ethnic groups, we calculate predicted probabilities for a number of different scenarios (see Figure 3). The top panel in Figure 3 pertains to the time period 2001 to 2005, while the bottom panel provides predicted probabilities for 2006 to 2010. From left to right, we first calculate predicted conflict contagion probabilities between two countries for different values of excluded ethnic groups in the sender state, while the potential receiver country has no excluded ethnic groups, which implies that the dyadic indicator is equal to zero. Holding all other variables at their mean values, we increase the number of excluded ethnic groups in the sender state from 0 to 10 and calculate predicted probabilities and $95 \%$ credible bands. Moving further to the right of Figure 3 , we repeat the same procedure to evaluate the substantial contagion risk that the exclusion of ethnic groups has on potential conflict receiving countries. Having assessed scenarios where only the receiver or sender exclude ethnic groups, we now investigate contagion risk increasing the number of excluded groups in the sender and receiver countries. We demonstrate that even though the estimated direct dyad effect is fairly small, there is an "indirect" dyad effect that increases the contagion risk considerably given that the baseline risk is fairly small.

Finally, we turn to the third-order network effects of our model. To allow an easier understanding of the network results, we visualize the mean positions of countries in the sender and receiver latent space for both observation periods (Figure 44). Countries that are close in the receiver latent space 
Firewall? Or, Wall on Fire?

receive conflict from a similar set of countries, while countries that are close in the sender latent space send conflict to a similar set of countries. Given the specified sender, receiver, and dyadic effects, the latent space allows us to assess whether there is structure in the $u_{i}^{\prime} v_{j}$ latent space pointing to third order network effects. We plot the mean positions of all countries in the latent receiver space and color the countries that experienced conflict as a function of their longitude and latitude. Countries in, e.g., South-East Asia are bright green while South American countries are dark red.

We first turn to the latent receiver space for 2001-2005 (Subfigure 4a). Generally, there is little support for third-order effects as most countries with (colored) and without conflict (gray) cluster in the middle of the space. However, in the upper hand of the plot there is a set of countries (in the Caucasus and Central Asia) that stand out. These countries are more likely to receive conflict from the same set of countries. In fact, the same countries are also more likely to send conflicts to a similar set of countries (Subfigure 4b). This finding provides support for the idea that, in this particular region, conflict trap mechanisms have an effect beyond the modeled sender, receiver, and dyad effects. As expected, once we explicitly model these 2001-2005 latent positions in our 2006-2010 contagion model, the regional third-order effects seem to disappear (see Subfigure 4d and Subfigure 4e). The results in the 2006-2010 contagion model indicate that countries that are closer in the latent space between 2001-2005 have a positive effect on conflict contagion (see Subfigure 2c). In addition, the effect of politically excluding ethnic groups in the sender and receiver country, decreases when controlling for the latent positions of the previous period (compare panels in Figure 3). These insights provide evidence that third-order network structures matter, but maybe not in all conflict regions.

5.4. Performance comparison to standard approach. As we argue that our empirical framework is an improved approach of assessing different theoretical aspects of conflict diffusion processes, we also provide insights how this approach fares vis-à-vis standard approach of modeling diffusion processes. Hence, we estimate a dyadic logit model that includes all information for the sender, receiver, and the dyad. Similarly to our main approach, we estimate two models for the respective time periods (2001-2005 and 2006-2010). We then compare the predictive performance by plotting separation plots and evaluating the specificity/sensitivity of all models. Separation plots provide a visual interpretation of model fit by plotting all observations in the data set according to their 
Firewall? Or, Wall on Fire?

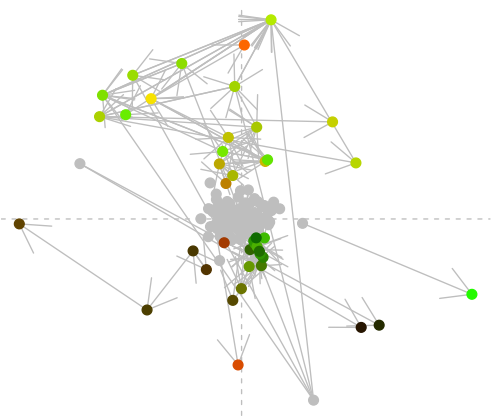

(A) Receiver Network (01-05)

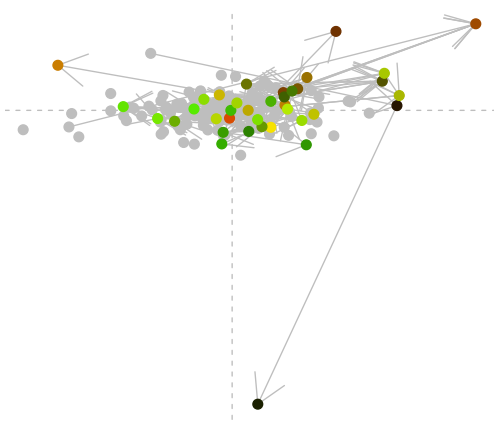

(B) Receiver Network (06-10)

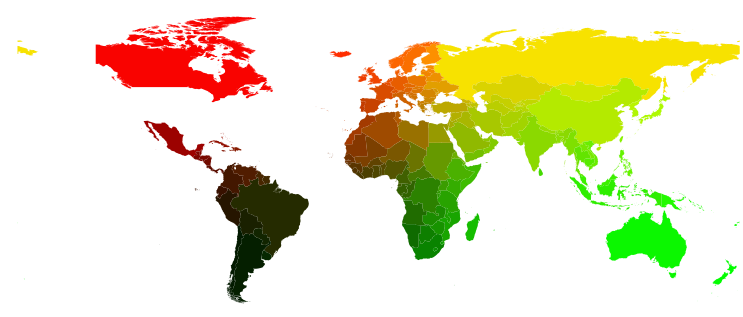

(C) Color Coded World Map

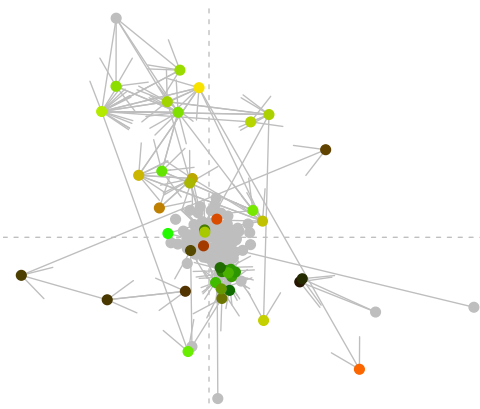

(D) Sender Network (01-05)

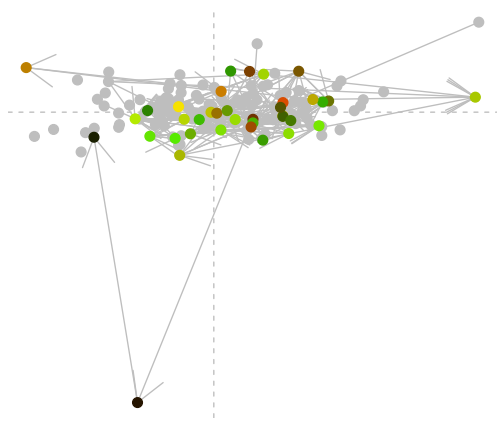

(E) Sender Network (06-10)

Figure 4. GBME Receiver and Sender Latent Space: Latent Space and Map Colored by Coordinates. Colored dots represent countries that sent or received a conflict in the observation period. Gray dots represent countries that did not send or receive conflict in the observation period. Arrows indicate the direction of conflict contagion. Gray dots that send conflict have experienced conflict in the previous observation period. 


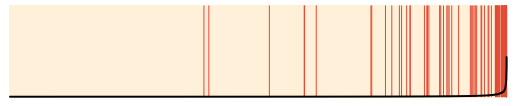

(A) Dyadic Logit Model (01-05)

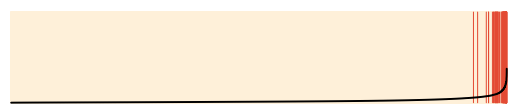

(c) GBME Model (01-05)

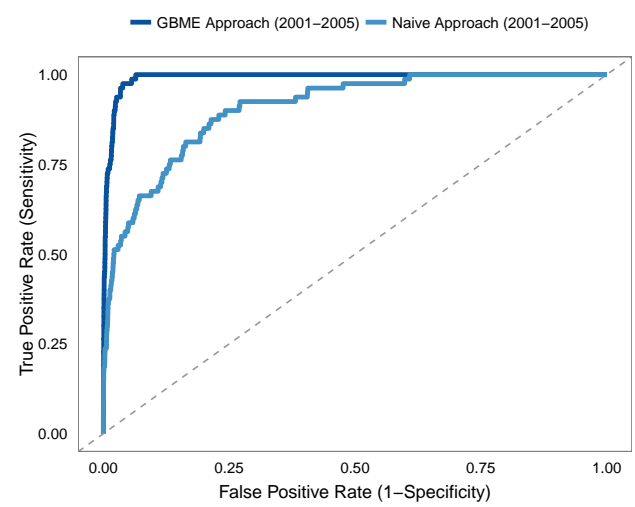

(E) Roc Curves (01-05)

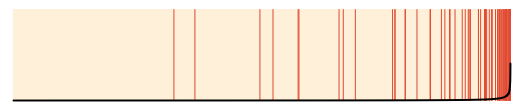

(B) Dyadic Logit Model (06-10)

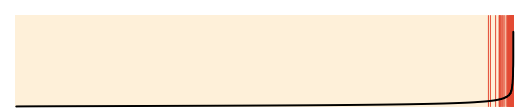

(D) GBME Model (06-10)

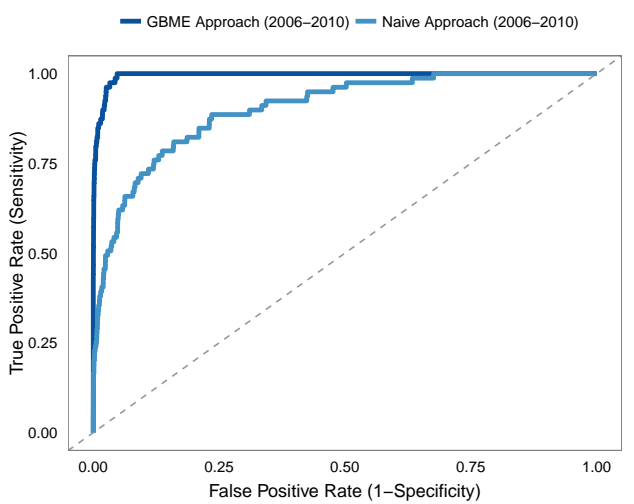

(F) Roc Curves (06-10)

Figure 5. Predictive performance of Logit vs. GBME model. Upper panels display separation plots, while the bottom panels provide ROC curves.

predicted value from left (low values) to right (high values). Observations that actually experience a contagion event are then colored red, leaving all other cases light yellow. This implies that models with a good model fit should should have all actual (red) observations towards the right of the separation plot (Greenhill, Ward and Sacks, 2011). In both time periods the GBME model outperforms the dyadic logit model. A more conventional procedure is to compare the sensitivity and specificity trade-off for each model with ROC curves. This type of analysis (see Figure 5 e and Figure 5f again shows the GBME approach clearly outperforms the dyadic logit model. Beyond this we note the AUC statistics are higher when employing the network formulation. In particular for both periods the network model has an AUC of 0.99, while the logistic model in the period from 2001-2005 has an AUC of 0.91 (and 0.90 from 2006-2010). The network model is therefore about $10 \%$ more accurate.

\subsection{Geographic proximity or does demonstration effects go beyond borders? Our main} analysis constraints contagion to take place between adjacent countries. This is in line with the existing literature that heavily focuses on the effect neighboring countries have on the risk of conflict spilling over. However, there is increasing evidence that immediate adjacency does not necessarily 
Firewall? Or, Wall on Fire?

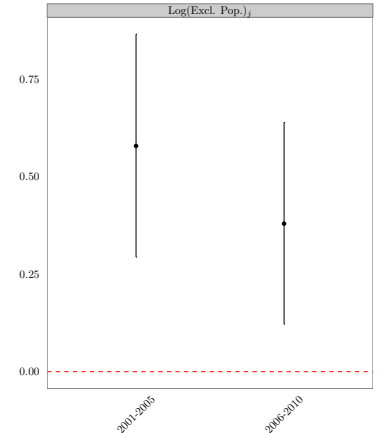

(A) Sender: Main

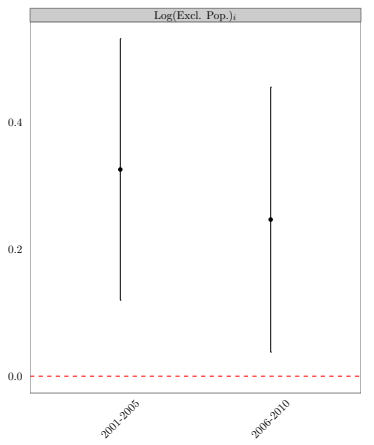

(D) Receiver: Main

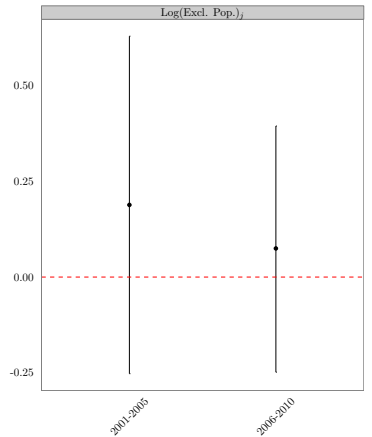

(B) Sender: $5 \mathrm{k} \mathrm{km}$

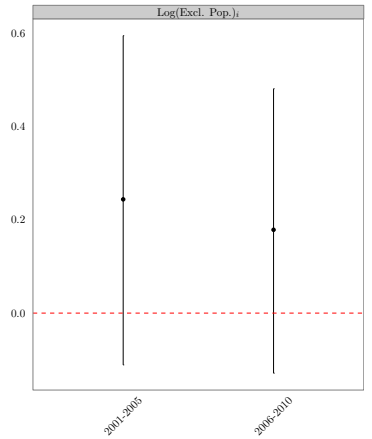

(E) Receiver: $5 \mathrm{k} \mathrm{km}$

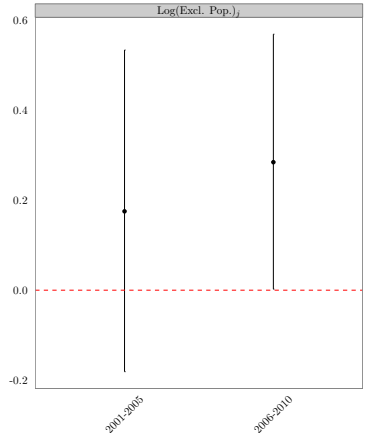

(c) Sender: $10 \mathrm{k} \mathrm{km}$

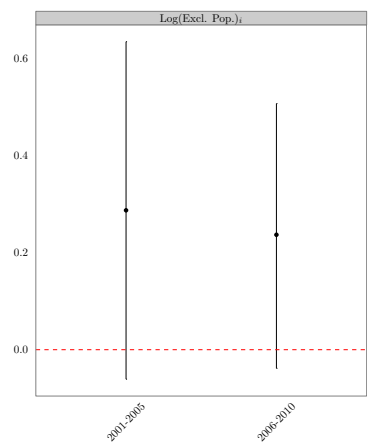

(F) Receiver: $10 \mathrm{k} \mathrm{km}$

Figure 6. Comparison of estimates of ethnic exclusion for different geographic cutoff points. First column displays estimates for ethnic exclusion from the main model. Second column for a cutoff of 5,000 km. Third column for a cutoff of 10,000 km

lead to a higher risk of conflict contagion (Hill and Rothchild, 1986; Beiser, 2011). We thus relax our operationalization of neighborhood and allow for potential spillovers to happen between countries whose centroid distance is $5,000 \mathrm{~km}$ and $10,000 \mathrm{~km}$ shown in Figure 6. These additional models seem to indicate that the effect of ethnic exclusion on spillovers becomes indistinguishable from zero when relaxing the adjacent operationalization of spillovers. While the estimated coefficients for our main explanatory variable remains positive, we cannot claim that ethnic exclusion has an effect beyond contiguous countries. This might imply that factors that are highly correlated to geographic proximity are conditioning the spillover effects. From out theoretical perspective these should be variables that enhance demonstration effects, for example, linguistic similarity or common media access. 
Firewall? Or, Wall on Fire?

\section{Conclusion}

Civil war contagion has received increased attention by research scholars and practitioners. We argued that we need to separate, theoretically and empirically, the effects senders, receivers, dyads, and larger network structures have on this phenomenon. Especially, sender and third-order effects have so far received little attention in the civil conflict literature. We believe that the approach presented here will help scholars to make further progress by providing an analytical framework to address all aspects that may be involved in civil war contagion.

We focused on the role that the political exclusion of ethnic groups has on conflict contagion. While it is well established that excluded ethnic groups impact on civil conflict onset Cederman, Wimmer and Min, 2010) and duration (Wucherpfennig et al., 2012), we contribute to a growing literature that links the political status of ethnic groups to conflict contagion Moore and Davis, 1997; Kuran, 1998; Forsberg, 2014b). Our empirical finding, that ethnic exclusion in the sender country plays an important role in explaining conflict contagion, has received almost no attention in the existing literature. This means important sender effects of the contagion process have so far been neglected in the literature and might shed new light on intervention strategies and conflict prevention Kathman, 2010, Beardsley, 2011). In line with current research, we also demonstrate that excluded ethnic groups impact on the risk of receiving conflict. This also relates with a more general argument that domestic characteristic matter for conflict contagion Maves and Braithwaite, 2013). However, in the context of ethnic exclusion, we find little support for direct dyadic effects that are frequently mentioned in current research. Of course, if countries $i j$ both politically exclude ethnic groups, they have a greater risk of conflict contagion, but this is simply the addition of sender and receiver effects.

In addition, we provided initial insights that the effect of ethnic exclusion on conflict contagion is dependent on geographic proximity. Further research has to explore whether there are factors that increase demonstration effects (e.g. linguistic similarities) and correlate with geographic proximity can account for this result. Our findings in regard to third-order network effects are less conclusive. While the lagged network positions in the 2006-2010 model have a positive effect on conflict contagion, the latent space only provides limited insights to where this effect comes from. A cautious interpretation of our results indicates that the network effect is driven by conflict traps in the Caucasus and Central Asia. 
Firewall? Or, Wall on Fire?

Finally, we believe that the identification of different contagion mechanisms will help to build better predictive models of conflict. Accounting for several contagion mechanisms should enable us to model this complex phenomenon. In further improving our network approach, future research needs to address the endogenous process of being part of the conflict network. Thus, first modeling the onset of conflict and then the contagion mechanism will be an important extension of our work. 
Firewall? Or, Wall on Fire?

Online Appendix

Appendix A.

TABle A1. Summary table of sender and receiver variables

\begin{tabular}{|c|c|c|c|c|c|}
\hline Variables & $\mathrm{N}$ & Mean & $\sigma$ & Min & $\operatorname{Max}$ \\
\hline \multicolumn{6}{|l|}{$2001-2005$} \\
\hline GDP per capitalog & 167 & 7.511 & 1.630 & 4.415 & 10.759 \\
\hline Population $_{l o g}$ & 167 & 15.919 & 1.667 & 11.305 & 20.964 \\
\hline Polity & 167 & 14.046 & 6.492 & 1.000 & 21.000 \\
\hline Excluded ethnic groups & 167 & 2.432 & 5.039 & 0.000 & 48.000 \\
\hline Proportion of mountainous terrain & 167 & 1.993 & 1.435 & 0.000 & 4.557 \\
\hline GDP Growth (past 5 years) & 167 & 3.998 & 7.031 & -11.144 & 60.771 \\
\hline \multicolumn{6}{|l|}{$2006-2010$} \\
\hline GDP per capita ${ }_{l o g}$ & 167 & 7.665 & 1.626 & 4.551 & 10.890 \\
\hline Population $_{\log }$ & 167 & 15.991 & 1.656 & 11.346 & 20.994 \\
\hline Polity & 167 & 14.840 & 6.443 & 1.000 & 21.000 \\
\hline Excluded ethnic groups & 167 & 2.359 & 5.034 & 0.000 & 48.000 \\
\hline Proportion of mountainous terrain & 167 & 1.993 & 1.435 & 0.000 & 4.557 \\
\hline GDP Growth (past 5 years) & 167 & 4.958 & 5.405 & -5.237 & 35.723 \\
\hline
\end{tabular}


Firewall? Or, Wall on Fire?

TABle A2. Sample: 167 countries. Dependent variable: Occurence of contagion event between 2001 to 2005 and 2006 to 2010. Independent variables: Each IV measured at initial value of time period. $95 \%$ credible interval for posterior means are shown in parentheses.

\begin{tabular}{|c|c|c|c|}
\hline & & $2001-2005$ & $2006-2010$ \\
\hline \multicolumn{4}{|l|}{ Dyadic Effects } \\
\hline Excl. $\quad$ Pop. $i, j$ & & $\begin{array}{c}-0.072 \\
(-0.460,0.318)\end{array}$ & $\begin{array}{c}0.048 \\
(-0.439,0.532)\end{array}$ \\
\hline$u_{i}^{\prime} v_{j}$ & & & $\begin{array}{c}0.571 \\
(0.475,0.667)\end{array}$ \\
\hline \multicolumn{4}{|l|}{ Sender Effects } \\
\hline $\log (\text { GDP per capita })_{i}$ & & $\begin{array}{c}-0.320 \\
(-0.446,-0.199)\end{array}$ & $\begin{array}{c}-0.128 \\
(-0.282,0.023)\end{array}$ \\
\hline $\log (\text { Population })_{i}$ & & $\begin{array}{c}0.141 \\
(0.062,0.220)\end{array}$ & $\begin{array}{c}0.139 \\
(-0.020,0.299)\end{array}$ \\
\hline Polity $_{i}$ & & $\begin{array}{c}0.018 \\
(-0.011,0.047)\end{array}$ & $\begin{array}{c}-0.047 \\
(-0.094,-0.000)\end{array}$ \\
\hline $\log (\text { Excl. } \quad \text { Pop. })_{i}$ & & $\begin{array}{c}0.579 \\
(0.294,0.866)\end{array}$ & $\begin{array}{c}0.380 \\
(0.121,0.640)\end{array}$ \\
\hline Prop. $\quad$ Mountainous $_{i}$ & & $\begin{array}{c}0.123 \\
(-0.048,0.298)\end{array}$ & $\begin{array}{c}-0.024 \\
(-0.218,0.168)\end{array}$ \\
\hline GDP Growth (Past 5 & $5{\text { Years })_{i}}$ & $\begin{array}{c}0.029 \\
(0.013,0.045)\end{array}$ & $\begin{array}{c}0.006 \\
(-0.028,0.041)\end{array}$ \\
\hline \multicolumn{4}{|l|}{ Receiver Effects } \\
\hline $\log (\text { GDP per capita })_{j}$ & & $\begin{array}{c}-0.159 \\
(-0.256,-0.067)\end{array}$ & $\begin{array}{c}-0.230 \\
(-0.417,-0.046)\end{array}$ \\
\hline $\log (\text { Population })_{j}$ & & $\begin{array}{c}0.115 \\
(0.032,0.196)\end{array}$ & $\begin{array}{c}0.024 \\
(-0.078,0.128)\end{array}$ \\
\hline Polity $_{j}$ & & $\begin{array}{c}-0.021 \\
(-0.047,0.005)\end{array}$ & $\begin{array}{c}-0.020 \\
(-0.051,-0.011)\end{array}$ \\
\hline Log(Excl. $\quad$ Pop. $)_{j}$ & & $\begin{array}{c}0.326 \\
(0.120,0.532)\end{array}$ & $\begin{array}{c}0.247 \\
(0.038,0.456)\end{array}$ \\
\hline Prop. $\quad$ Mountainous $_{j}$ & & $\begin{array}{c}0.043 \\
(-0.093,0.175)\end{array}$ & $\begin{array}{c}-0.006 \\
(-0.170,0.158)\end{array}$ \\
\hline GDP Growth (Past 5 & $5{\text { Years })_{j}}$ & $\begin{array}{c}0.009 \\
(-0.009,0.027)\end{array}$ & $\begin{array}{c}0.019 \\
(-0.006,0.044)\end{array}$ \\
\hline \multicolumn{4}{|l|}{ Dependencies } \\
\hline Common Sender $\sigma_{a}^{2}$ & & 3.743 & 1.855 \\
\hline Sender-Receiver $\quad \sigma_{a, b}^{a}$ & & 2.860 & 1.513 \\
\hline Common Receiver $\sigma_{b}^{2}$ & & 2.797 & 1.599 \\
\hline Reciprocity $\rho$ & & 0.459 & 0.454 \\
\hline
\end{tabular}


Firewall? Or, Wall on Fire?

\section{REFERENCES}

Beardsley, Kyle. 2011. "Peacekeeping and the Contagion of Armed Conflict." The Journal of Politics 73(04):1051-1064.

Beiser, Janina. 2011. Looking Beyond Borders: Identification, Information, and Ethnic Conflict Contagion. Technical report Working paper: University College London.

Black, Nathan. 2013. "When have violent civil conflicts spread? Introducing a dataset of substate conflict contagion." Journal of Peace Research 50(6):751-759.

Boschee, Elizabeth, Jennifer Lautenschlager, Sean O'Brien, Steve Shellman, James Starz and Michael D. Ward. 2015. "ICEWS Coded Event Data." http://dx.doi.org/10.7910/DVN/28075 Harvard Dataverse Network [Distributor] V1 [Version].

Braithwaite, Alex. 2010. "Resisting infection: How state capacity conditions conflict contagion." Journal of Peace Research 47(3):311-319.

Buhaug, Halvard and Kristian Skrede Gleditsch. 2008. "Contagion or confusion? Why conflicts cluster in space." International Studies Quarterly 52(2):215-233.

Cederman, Lars-Erik, Andreas Wimmer and Brian Min. 2010. "Why do ethnic groups rebel? New data and analysis." World Politics 62(1):87-119.

Cederman, Lars-Erik, Kristian Skrede Gleditsch, Idean Salehyan and Julian Wucherpfennig. 2013. "Transborder Ethnic Kin and Civil War." International Organization 67(02):389-410.

Cederman, Lars-Erik, Luc Girardin and Kristian Skrede Gleditsch. 2009. "Ethnonationalist Triads: Assessing the Influence of Kin Groups on Civil Wars." World Politics 61(3):403-437.

Danneman, Nathan and Emily Hencken Ritter. 2014. "Contagious Rebellion and Preemptive Repression." Journal of Conflict Resolution 58(2):254-279.

De Groot, Olaf J. 2011. "Culture, Contiguity and Conflict: On the measurement of ethnolinguistic effects in spatial spillovers." The Journal of Development Studies 47(3):436-454.

Fearon, James D. and David D. Laitin. 2003. "Ethnicity, insurgency, and civil war." American Political Science Review 97(1):75-90.

Forsberg, Erika. 2008. "Polarization and Ethnic Conflict in a Widened Strategic Setting." Journal of Peace Research 45(2):283-300.

Forsberg, Erika. 2014a. "Diffusion in the Study of Civil Wars: A Cautionary Tale." International Studies Review 16(2):188-198. 
Firewall? Or, Wall on Fire?

Forsberg, Erika. 2014b. "Transnational Transmitters: Ethnic Kinship Ties and Conflict Contagion 1946-2009." International Interactions 40(2):143-165.

Fox, Jonathan. 2004. "Is ethnoreligious conflict a contagious disease?" Studies in Conflict and Terrorism 27(2):89-106.

Franzese, Robert J. and Jude C. Hays. 2008. "Interdependence in Comparative Politics: Substance, Theory, Empirics, Substance." Comparative Political Studies 41(4/5):742-780.

Garcia, Blake E. and Cameron Wimpy. 2015. "Does Information Lead to Emulation? Spatial Dependence in Anti-Government Violence." Political Science Research and Methods FirstView:120.

Gleditsch, Kristian Skrede. 2002a. All International Politics is Local: The Diffusion of Conflict, Integration, and Democratization. Ann Arbor: University of Michigan Press.

Gleditsch, Kristian Skrede. 2002b. "Expanded trade and GDP data." Journal of Conflict Resolution $46(5): 712-724$.

Gleditsch, Kristian Skrede. 2007. "Transnational dimensions of civil war." Journal of Peace Research 44(3):293-309.

Gleditsch, Kristian Skrede, Idean Salehyan and Kenneth Schultz. 2008. "Fighting at Home, Fighting Abroad." Journal of Conflict Resolution 52(4):479-506.

Greenhill, Brian D., Michael D. Ward and Audrey Sacks. 2011. "The Separation Plot: A New Visual Method for Evaluating the Fit of Binary Models." American Journal of Political Science 55(4):991-1003.

Gurr, Ted Robert. 1993. "Why minorities rebel: A global analysis of communal mobilization and conflict since 1945." International Political Science Review 14(2):161-201.

Heider, Fritz. 1946. "Attitudes and cognitive organization." Journal of Psychology 21(1):107-112.

Hill, Stuart and Donald Rothchild. 1986. "The Contagion of Political Conflict in Africa and the World." Journal of Conflict Resolution 30(4):716-735.

Hoff, Peter D. 2005. "Bilinear Mixed-Effects Models for Dyadic Data." Journal of the American Statistical Association 100(4690):286-295.

Hoff, Peter D. 2007. "Extending the Rank Likelihood for Semiparametric Copula Estimation." Annals of Applied Statistics 1(1):265-283.

Horowitz, Donald L. 1985. Ethnic groups in conflict. Berkeley: University of California Press. 
Firewall? Or, Wall on Fire?

Kathman, Jacob D. 2010. "Civil War Contagion and Neighboring Interventions." International Studies Quarterly 54(4):989-1012.

Kuran, Timur. 1998. Ethnic Dissimilation and its International Diffusion. In The International Spread of Ethnic Conflict: Fear, Diffusion, and Escalation, ed. David A. Lake and Donald S. Rothchild. Princeton: Princeton University Press pp. 35-60.

Maves, Jessica and Alex Braithwaite. 2013. "Autocratic Institutions and Civil Conflict Contagion." The Journal of Politics 75:478-490.

Moore, Will H. and David R. Davis. 1997. "Ethnicity matters: Transnational ethnic alliances and foreign policy behavior." International Studies Quarterly 41(1):171-184.

Murdoch, James D. and Todd Sandler. 2004. "Civil wars and economic growth: Spatial dispersion." American Journal of Political Science 48(1):138-151.

O’Brien, Sean P. 2010. "Crisis Early Warning and Decision Support: Contemporary Approaches and Thoughts on Future Research." International Studies Review 12(1):87-104.

Salehyan, Idean and Kristian Skrede Gleditsch. 2007. "Refugees and the Spread of Civil War." International Organization 60(2):335-366.

Schultz, Kenneth A. 2010. "The Enforcement Problem in Coercive Bargaining: Interstate Conflict over Rebel Support in Civil Wars." International Organization 64(02):281-312.

Simmons, Beth A. and Zachary Elkins. 2004. "The globalization of liberalization: Policy diffusion in the international political economy." American Political Science Review 98(1):171-189.

Starr, Harvey and Benjamin A Most. 1976. "The Substance and Study of Borders in International Relations Research.” International Studies Quarterly 20(4):581-620.

Ward, Michael D., John S. Ahlquist and Arturas Rozenas. 2012. "Gravity's Rainbow: A Dynamic Latent Space Model for the World Trade Network." Network Science 1(1):95-118.

Ward, Michael D., Nils W. Metternich, Cassy Dorff, Max Gallop, Florian Hollenbach, Anna Schultz and Simon Weschle. 2013. "Stepping into the Future: A new generation of conflict forecasting models." International Studies Review 15(4).

Wasserman, S. and K. Faust. 1994. Social Network Analysis: Methods and Applications. Cambridge: Cambridge University Press.

Wucherpfennig, Julian, Nils W. Metternich, Lars-Erik Cederman and Kristian Skrede Gleditsch. 2012. "Ethnicity, the state, and the duration of civil war." World Politics 64(1):79-115. 
Firewall? Or, Wall on Fire?

Young, Crawford. 2006. "The Heart of the African Conflict Zone: Democratization, Ethnicity, Civil Conflict, and the Great Lakes Crisis." Annual Review of Political Science 9:301-328. 
Firewall? Or, Wall on Fire?

Nils W. Metternich: Department of Political Science

Current address: University College London, London, WC1H 9QU, UK

E-mail address: n.metternich@ucl.ac.uk

Shahryar Minhas: Department of Political Science

Current address: Duke University, Durham, NC, 27708, USA

E-mail address: sfm12@duke.edu

Michael D. Ward: Department of Political Science

Current address: Duke University, Durham, NC, 27708, USA

E-mail address: mw160@duke.edu 